\title{
Reliance on orthography and phonology in reading of Chinese: A developmental study
}

\author{
Wei Zhou \\ Beijing Key Lab of Learning and Cognition, Department of Psychology, Capital \\ Normal University, Beijing, China and Beijing Advanced Innovation Center for \\ Imaging Technology, Capital Normal University, Beijing, China
}

\section{Hua Shu}

State Key Laboratory of Cognitive Neuroscience and Learning and IDG/McGovern Institute for Brain Research, Beijing Normal University, China

\section{Kevin Miller}

Departments of Educational Studies and Psychology, University of Michigan, Ann Arbor, USA

\section{Ming Yan}

Department of Psychology, University of Potsdam, Potsdam, Germany

Background: Disruptions of reading processes due to text substitutions can measure how readers use lexical information.

Methods: With eye-movement recording, children and adults viewed sentences with either identical, orthographically similar, homophonic or unrelated substitutions of the first characters in target words. To the extent that readers rely on orthographic or phonological cues, substitutions that contain such cues should cause less disruption reading than do unrelated substitutions.

Results: On pretarget words, there was a reliable reduction in gaze duration due to homophonic substitution only for children. On target words, we observed reliable recovery effects due to orthographic similarity for adults. On post-target words, adults had better orthographic-based and phonological-based recovery abilities than children.

Conclusions: The combination of eye movement recording and the error detection paradigm offers a novel implicit paradigm for studying reading development: during sentence reading, beginning readers of Chinese may rely on phonological mediation, while skilled readers have more direct access to semantics from orthography.

What is already known about this topic

- There is little evidence for early phonological activation during the reading of Chinese sentences among skilled Chinese readers

- There is a rich body of evidence supporting the view that phonological information is activated very early in alphabetic scripts, as indexed by shorter fixation durations 
when useful phonological information is present.

\section{What this paper adds}

- Chinese beginning readers have early parafoveal activation of phonology during the silent reading of Chinese sentences, as indexed by the parafovea-on-fovea effect in the homophonic substitution condition.

- The early activation of phonology diminishes with the development of reading skills.

\section{Implications for theory, policy or practice}

- The phonological parafovea-on-fovea effect was revealed during the silent reading of Chinese sentences for beginning readers.

- Chinese children may rely on phonological codes while skilled readers have more direct access to semantics from orthography.

- The teaching of phonological aspects of Chinese orthography is very important for beginning readers

The use of lexical information in reading has been hotly debated for decades. According to cognitive models of word reading (e.g., M. Coltheart, Rastle, Perry, Langdon, and Ziegler, 2001; Plaut, McClelland, Seidenberg, and Patterson, 1996; Seidenberg and McClelland, 1989), semantics can be accessed either directly from orthography or indirectly via phonological mediation. Further, whether the phonological route or the direct route serves as the predominant route in word recognition and reading depends on reading skill. Some have argued that silent reading is a relatively late invention (Laubrock and Kliegl, 2015; Manguel, 1996; Saenger, 1997), although others have questioned this claim (e.g., Gilliard, 1993). Developmentally, reading aloud precedes silent reading (Laubrock and Kliegl, 2015; Manguel, 1996). This leads to the conclusions that beginning readers are likely to rely on phonological information but that as they become more skilled, readers increasingly shift to an orthographic procedure that takes advantage of proficient phoneme-grapheme conversion (Ehri, 1992; Frith, 1985; Seymour, 1997). One piece of evidence for this hypothesis was obtained from the study of Doctor and Coltheart (1980). In their experiments, children from 6 to 10 years old judged the meaningfulness of sentences. Sentences with a typographic error should be identified as meaningless. Their results showed that children were likely to falsely accept sentences with homophonic errors as meaningful ones. Additional analysis indicated that this difference could not be explained by visual similarity effects or an inability to spell homophones.

Another important finding reported by Doctor and Coltheart (1980) was that the false acceptance rate for homophonic errors decreased markedly with increasing age. Despite this drop in error rate, studies have consistently shown that even adult readers produce more false-positive judgments on wrong sentences containing homophonic errors than other errors (V. Coltheart, Avons, and Trollope, 1990; Treiman, Freyd, and Baron, 1983). These homophone effects among children and adult readers suggest that alphabetic readers continue to access phonological representations during silent reading irrespective of their reading skills, arguably, due to the sequential activation of a lexical route from orthography to phonology to semantics (Van Orden, 1987).

\section{The error disruption paradigm}

In an effort to find more sensitive techniques than sentence acceptability decisions, Daneman and Reingold (1993) introduced the error disruption paradigm to provide an 
implicit measure of the reliance on orthographic or phonological processing in natural reading. Subjects read sentences with correct target words (e.g., He wore blue jeans) as well as those with spelling errors that were either homophones (e.g., He wore blew jeans) or control words that were nonhomophonic but orthographically similar to targets (e.g., He wore blow jeans). The rationale of this paradigm is that, to the extent that readers rely on some features (e.g., phonology or orthography) in reading, substitutions which preserve that feature (homophones or orthographically similar words) should be less disruptive to reading than are other substitutions.

The error disruption paradigm has been widely used to test the kind of information readers rely on, and there is much evidence supporting the view that phonology is activated very early in alphabetic scripts. In English, for example, Rayner, Pollatsek, and Binder (1998) reported shorter first-fixation durations (FFDs; durations of the first fixation on a word, irrespective of the number of fixations) on the target words for sentences with homophonic words as compared to visually similar non-homophones, irrespective of levels of orthographic similarity (i.e., the number of overlapping letters). Recently, Jared, Ashby, Agauas, and Levy (2016) reported shorter initial reading times on homophonic errors relative to spelling controls and proposed that phonology contributes to access of word meanings in Grade 5 English readers. Similar results were reported in some other studies (e.g., Inhoff and Topolski, 1994; Sparrow and Miellet, 2002).

In a cross-language study, Feng, Miller, Shu, and Zhang (2001) reported the standard finding of early phonological effects in English but did not find the use of early phonological information during the reading of Chinese sentences among skilled Chinese readers. This finding raises an important developmental question. Is the lack of early phonological access an inherent feature of Chinese that would affect all readers, or does it represent a late development as skilled readers are able to use an orthographic route in reading? We demonstrate in the present study a different developmental trajectory in terms of phonological recoding for Chinese as compared to alphabetic readers: due to language-specific properties of Chinese which we elaborate on below, Chinese unskilled readers have early activation of phonology during the silent reading, and this early activation decreases with the development of reading skill.

\section{The use of phonology in Chinese}

Due to the nature of alphabetic writing, it is difficult to find homophonic word pairs with low visual similarity in English. In Chinese, however, the relatively independent relationship between orthography and phonology offers a unique opportunity to dissociate these factors. As a logographic writing system, one fundamental difference from alphabetic writing systems is that Chinese characters represent morphemic units and are formed in a variety of ways that may not directly represent the sounds of those morphemes (Hoosain, 1991). Because Mandarin has only about 1,200 syllables (and many more characters than that), there are very many homophonic characters. The basic writing unit in Chinese is the character, consisting of strokes and radicals in a square-shaped spatial configuration. Different types of Chinese characters are optimised for direct semantic extraction: The majority of ancient characters belong to pictographs and ideograms, which was derived from drawings by the ancients or created through association or analogy. These characters usually have low visual complexity and high frequency and often have no connection to their pronunciation. 
A large number of modern Chinese characters belong to phonograms which in most cases combine two simple characters in a horizontal or vertical arrangement. One of the simple characters provides a clue to the meaning of the compound character, and it is therefore called the semantic radical; whereas the other one, the phonetic radical, relates to the pronunciation of the compound character. Nevertheless, as a result of the development of the Chinese writing system over centuries, this sublexical/radical clue to the pronunciation is very unreliable, and less than $30 \%$ of modern phonograms are pronounced the same as their phonetic radicals (Lee, Tsai, Su, Tzeng, and Hung, 2005; Zhou, 1978).

Taken together, the orthography-to-phonology mapping in Chinese is inconsistent and often opaque; thus, Chinese is normally considered a writing system with deep orthography. Previous studies of Chinese reading have suggested that phonological mediation can be bypassed and semantic information is usually accessed directly from orthography (e.g., Chen and Shu, 2001; Zhou and Marslen-Wilson, 1999). More relevant to the context of the present study, the unique roles of phonology and orthography in Chinese reading were examined by Wong and Chen (1999) using the error disruption paradigm: target characters, which were presented as the first characters of two-character words, were replaced by visually similar, homophonic or unrelated characters. They found that there were significant shorter FFD and gaze duration (GD, the cumulative duration of all fixations during the first-pass reading of the word) on target word region in the orthographically similar condition as compared to the unrelated condition. On the other hand, there was only a weak effect in the post-target region for the homophone condition. In addition, they have found that word-based fixation duration was more sensitive to the different kinds of errors relative to character-based eye-movement measures. So the manipulation of embedding the target character as the first character in the two-character word has been frequently used in previous research (e.g., Feng et al., 2001; Yan, Richter, Shu, and Kliegl, 2009). As character identification may be influenced when the character is part of a word (e.g., Cheng, 1981; Wheeler, 1970), the present study used the same target word (i.e., within-item manipulation) to construct all error conditions and controlled the properties (i.e., character frequency, number of strokes, combinability, and boundedness, see Method for details) of the first characters.

The experimental evidence reviewed above indicates that phonological mediation before access to word meaning might be more relevant to alphabetic writing systems such as English compared to Chinese. For example, Feng et al. (2001) compared how readers of English and Chinese rely on orthography and phonology in reading and reported evidence for very early phonological activation in English, but not in Chinese. On the other hand, homophonic errors demonstrated a recovery benefit in later processing in both writing systems. Adult college students are expert readers, and studying beginning readers of Chinese is critical to understanding the role of orthography and phonology in the development of skilled reading.

\section{Acquirement of information from the parafovea}

During sentence reading, the effective area of vision (i.e., the perceptual span; McConkie and Rayner, 1975) extends beyond the currently fixated word/character. In Chinese, the span extends one character to the left and up to three or four characters to the right of the current fixation (Inhoff and Liu, 1998; Pan, Yan, and Laubrock, 2017; Yan, Zhou, Shu, and Kliegl, 2015), indicating that reading involves extraction of information not only 
from the fixated words in the fovea but also from the upcoming words in the parafovea. While traditional behavioural studies have revealed basic cognitive mechanisms of single foveal word reading, the eye movement recording in naturalistic sentence reading can examine the early processing of the upcoming parafoveal word. One way of measuring parafoveal information processing is to test whether fixation durations on the currently fixated words can be influenced by properties of the upcoming parafoveal words which have not been fixated yet, namely the parafoveal-on-foveal (POF) effects. Because information is more densely packed in Chinese, it is not surprising that POF effects have been reported during the reading of Chinese sentences (e.g., Yan and Sommer, 2015; Yan et al., 2009; Yang, Wang, Xu, and Rayner, 2009) whereas such effects in alphabetic scripts are less robust (see Kliegl, Risse, and Laubrock, 2007, for a review).

Because of the fast access to semantics and the eccentricity advantage for parafoveal words in Chinese, a common prediction is that parafoveal phonological information may not be very beneficial among skilled Chinese readers. Two studies tested different kinds of POF effects. Yan et al. (2009) observed no homophonic POF effects during the silent reading of Chinese sentences. In a follow-up study, Pan, Laubrock, and Yan (2016) replicated the absence of homophonic POF effect in silent reading and reported that such an effect was limited to oral reading in which the demands of reading aloud enhanced sensitivity towards phonological information in the parafovea. Unfortunately, none of the studies tested parafoveal processing of phonology from a developmental perspective. This is important because reliance on different types of information for foveal lexical access shifts during language development. For instance, phonological processing plays a more important role than orthographic processing in early reading-spelling acquisition (Sprenger-Charolles, Siegel, Béchennec, \& Serniclaes, 2003a; Ziegler, Bertrand, Lété, and Grainger, 2014). Therefore, we predict that this may also be the case for parafoveal processing, that is, beginning readers benefit more from parafoveal phonology than adults do.

\section{The present study}

Reading acquisition requires not only orthographic skills but also phonological skills (Ho and Bryant, 1997; Hu and Catts, 1998; Huang and Hanley, 1995; Shu, Peng, and McBride-Chang, 2008; Siok and Fletcher, 2001). Hu and Catts (1998) proposed that the association between early reading ability and phonological skill is not confined to reading an alphabetic orthography but applicable to logographic orthographies as well. The absence of early phonological activation among Chinese adults (Feng et al., 2001) need not imply that the same is true for beginning readers. In order to investigate this, the present study used the error disruption paradigm and the types of substitutions designed in Wong and Chen (1999) to test orthographic and phonological activation among beginning and skilled Chinese readers. We also looked at whether phonological information in the parafovea affects fixation durations on pretarget region, leading to a POF effect. Therefore, together with target word and post-target word regions which are normally included for data analyses in previous studies, we also analysed fixations on pretarget words. Given the importance of phonological processing among beginning Chinese readers and the direct access to semantics among skilled Chinese readers, it is reasonable to predict that homophonic errors should be more disruptive for adults than for children. On the other hand, due to more efficient orthography-based processing among skilled readers, we also predict orthographic substitution should be more disruptive for children than for adults. 


\section{Method}

\section{Participants}

Thirty-six third graders (age $M=9.1$ years, $S D=0.3$ ) from a primary school in Beijing and thirty-six undergraduate college students (age $M=22.8$ years, $S D=2.0$ ) from the Beijing Normal University were recruited in the eye-movement experiment. In addition, two independent groups of subjects for norming studies were recruited: 24 undergraduate students (age $M=20.9, S D=2.0$ ) for an orthographic similarity rating and 20 participants (10 children, age $M=9.3, S D=0.4$ and 10 adults, age $M=20.7, S D=2.1$ ) for a familiarity rating.

All of the subjects were native speakers of Chinese, with normal or corrected-to-normal visual acuity and had not received any linguistics/psychology training before. All children received a book as a gift, and all adults were paid for their participation.

\section{Material}

A total of 88 two-character target words were created and embedded into sentence frames which were chosen and edited from textbooks used in grade 1 to 3 as shown in the Appendix. There were 33 coordinative, 38 modifier-head, 10 verb-object and 7 verb-complement compounds. Five children, who did not participant in the eye tracking study, proofread the sentences and reported no unfamiliar words. The first character of each target word was replaced by an identical, a homophonic, an orthographically similar or an unrelated substitution. Although there are a large proportion of phonograms in modern Chinese characters, for beginning readers, the most common characters are very often pictograms and ideograms (Shu, Chen, Anderson, Wu, and Yue, 2003). For the reasons of readability and representative, our critical characters therefore include mainly non-phonograms $(89 \%, 89 \%$ $82 \%$ and $90 \%$ for identical, orthographic, homophonic and unrelated substitution conditions, respectively). There was no significant difference in percentage of non-phonograms among the four conditions $\left[\chi^{2}(3)=.47, p=.926\right]$.

We used a within-item design, that is, the sentence frames, including pre-target and posttarget words, were identical across the experimental conditions. Therefore, any differences in the pretarget, target and post-target regions should only be due to the experimental manipulation and not to other word- or sentence-level factors. As shown in Table 1, different types of characters were closely matched in a number of linguistic properties including (1) character frequencies based on a corpus for adults [Beijing Language Institute Publisher, $1986 ; F(3,348)=.361, p=.781]$ and a corpus for children [Tao, 2012; $F(3,348)=.056$, $p=.983]$, (2) visual complexity as indexed by number of strokes $[F(3,348)=.024$, $p=.995]$, (3) character combinability which is defined as how likely a character appears as the first character in multi-character words [Tsai and Lee, 2008; $F(3,348)=1.421$, $p=.236$ ] and (4) percentage of bound or free morphemes (a free morpheme can combine words with different lexemes; e.g., Taft and Zhu, 1995) $\left[\chi^{2}(3)=6.21, p=.120\right]$.

We conducted two norming studies. First, orthographic similarities between the target characters and the three types of non-identical substitutions were assessed on a 5-point scale. The norming participants were instructed to mark on a 5-point scale (with 1 = 'very different' and $5=$ 'very similar') the orthographic similarity between each character pair. There was a significant main effect of orthographic similarity $[F(2,174)=1,279.483, p<.001]$ in the expected direction: multiple comparisons revealed larger visual similarity to the target characters for the orthographically similar substitutions, than for both the homophonic 
Table 1. Character properties.

\begin{tabular}{|c|c|c|c|c|}
\hline & \multicolumn{4}{|c|}{ Type of substitution } \\
\hline & Identical & Orthographic & Phonological & Unrelated \\
\hline Example & 木 & 水 & 目 & 及 \\
\hline Pronunciation & mu4 & shui3 & mu4 & ji2 \\
\hline Frequency.A & $864(1,538)$ & $763(1,094)$ & $745(1,370)$ & $678(582)$ \\
\hline Frequency.C & $594(1,064)$ & $589(920)$ & $563(1,052)$ & $543(654)$ \\
\hline N. of strokes & $5.7(2.2)$ & $5.6(2.1)$ & $5.6(1.9)$ & $5.7(1.8)$ \\
\hline Ortho. rating & - & $3.9(0.6)$ & $1.3(0.3)$ & $1.3(0.3)$ \\
\hline $\begin{array}{l}\text { Familiarity rating } \\
\text { (adults) }\end{array}$ & $4.9(0.3)$ & $4.8(0.4)$ & $4.9(0.2)$ & $4.9(0.2)$ \\
\hline $\begin{array}{c}\text { Familiarity rating } \\
\text { (children) }\end{array}$ & $4.3(0.4)$ & $4.2(0.6)$ & $4.3(0.5)$ & $4.4(0.4)$ \\
\hline
\end{tabular}

Note. Means (and standard deviations in parenthesis) of character frequencies (per million) based on corpus for adults (Frequency.A) and children (Frequency.C), number of strokes, orthographic relatedness between nonidentical substitutions and the identical character, and familiarity rating of characters to subjects. The target word (木偶, puppet) is embedded into a sentence (老师带领同学们参观木偶表演和各种杂技), which is translated as: The teacher led students to watch the puppet show and acrobatics.

$[F(1,87)=1,593.645, p<.001]$ and the unrelated substitutions $[F(1,87)=1,373.322$, $p<.001]$. There was no significant difference between the homophonic and the unrelated substitutions $[F(1,87)=0.078, p=.781]$. Second, we collected familiarity rating data for the substitutive characters on a 5-point scale (with $1=$ 'very unfamiliar' and 5 = 'very familiar'). There was no difference among the experimental conditions with respect to familiarity of the substitutive characters for adults $[F(3,348)=.048, p=.603]$ or for children $[F(3$, 348) $=1.070, p=.362]$.

The experimental sentences were $15-21$ characters in length $(M=16.9, S D=1.4)$. The pretarget, target and post-target words were all consisted of two characters, and they never appeared among the first two or the last two words (see Figure 1). Each sentence was presented only once to a participant with all of the conditions counterbalanced over participants. In this way, each participant read 88 sentences ( 22 per condition) which were presented randomly during the experiment.

\section{老师带领同学们参观水偶表演和各种杂技。Orthographic Substitution \\ 老师带领同学们参观目偶表演和各种杂技。Homophonic Substitution \\ 老师带领同学们参观及偶表演和各种杂技。Unrelated Substitution \\ 老师带领同学们参观木偶表演和各种杂技。Identical Substitution}

\section{Pretarget Target Post-target}

Figure 1. An example sentence displayed with different substitution conditions. Frames are used to highlight the pretarget, target and post-target words for the purposed of illustration but not during the experiment. The sentence is translated as: The teacher led students to watch the puppet show and acrobatics. 


\section{Apparatus}

An EyeLink CL desktop system at a sampling rate of 1,000 Hz was used to record readers' eye movements. All calibrations and recordings were based on the right eye. Single-line sentences were displayed on a ViewSonic G220f 21-inch CRT monitor (frame rate, $85 \mathrm{~Hz}$; resolution, 1,024 by 768 pixels) controlled by a dual-core processor computer running at $3.2 \mathrm{GHz}$ under Windows XP environment. Subjects were seated at a distance of $62 \mathrm{~cm}$ away from the monitor. Characters were displayed using the font Song 40, and each character subsumed $1.4^{\circ}$ of visual angle.

\section{Procedure}

Each subject performed a 9-point calibration and a validation of calibration accuracy before the test started. Then, a black circle for fixation was presented on the left side of the monitor. Fixation on the black circle would initiate the presentation of a sentence with the centre of its first character at the original fixation-point position. The experimenter would do recalibration if the tracker failed to detect the gaze point around the designated fixation point.

We instructed the subjects to read the sentences silently for comprehension, then fixate a dot at the low right corner of the screen and finally press a button to indicate the completion of reading. On 30 randomly selected trials, the sentences were followed by another screen for easy yes-no questions related to the meaning of the whole sentences. The subjects were requested to judge the correctness of the questions with two designated buttons. These questions served primarily to encourage reading for comprehension. Children and adults correctly answered $82 \%(S D=6 \%)$ and $95 \%(S D=6 \%)$ of all questions, respectively, which means that they understood the sentences quite well. The whole experimental session lasted for about $30 \mathrm{~min}$.

\section{Data analysis}

An algorithm for saccade detection (Engbert and Kliegl, 2003) was adopted to determine fixations. Sentences containing blinks, extremely low numbers of effective fixations (i.e., less than 2), coughs or body movements during data collection were deleted (i.e., $8 \%$ and $3 \%$ trials for children and adults, respectively). Similar to previous studies in Chinese (e.g., Feng et al., 2001; Yan et al., 2009), the data analyses were performed within twocharacter words regions. This was because of several reasons: First, the skipping rate of single characters is very high. Second, word-based fixation duration measures are known to be more sensitive to lexical processing than character-based measures (e.g., Wong and Chen, 1999).

For analyses on pretarget words and target words, trials with regressive saccades were removed because they could indicate incomplete processing of parafoveal words or the fixated words; pretarget, target and post-target words with FFDs longer than 1,000 ms or shorter than $60 \mathrm{~ms}$, or GDs longer than 1,500 ms were excluded from analyses. Taking the data filters together, for analyses on the pretarget, target and post-target regions, 2,541, 2,389 and 2,696 observations (i.e., 88\%, 84\% and 97\%) for children, and 2,795, 2,758 and 2,665 (i.e., $98 \%, 96 \%$ and 96\%) observations for adults were included.

Inferential statistics were based on a treatment contrast with the unrelated character substitution as a reference condition for the other three conditions; the reductions in fixation durations for the identical, orthographically similar and homophonic conditions 
were tested. We also specified a second fixed factor for group effect as well as the interaction between these two fixed factors. In addition, model parameters of variance components for participants and items as well as participant-related experimental main effects (i.e., varying intercepts and slopes) were estimated. Estimates were based on linear mixed models (LMMs) for FFD and GD analyses, using the lmer program of the lme4 package (Bates, Maechler, Bolker, and Walker, 2016; version 1.1-12) in the R software for statistical calculation (R Core Team, 2016; version 3.3.2). Estimates larger than 1.96 times of their standard errors are treated as significant at the 0.05 level. This is because given the small number of fixed and random effects and the large number of observations estimated, the $t$-statistic (M/SE) effectively corresponds to the $z$-statistic. Analyses of residuals and inspection of duration-distributions strongly suggested that log-transformation was required to meet LMM assumptions. Therefore, we used log-transformed durations for LMMs (Kliegl, Masson, and Richter, 2010).

\section{Results}

\section{Pretarget word region}

Because of the identical sentence frames including the pretarget words across the experimental conditions, any differences can be attributed to the manipulation of the targets. In other words, here we test a POF effect: whether processing of the pretarget word is influenced by properties of the parafoveal target word. As shown in Figure 2 and Table 2, skilled readers had shorter GDs than beginning readers $(b=-.541, S E=.046$, $t=-11.7)$. Relative to the unrelated condition, the main effects of identical, orthographic and homophonic POF effects were all highly reliable in GD $(b=-.059, S E=.016$, $t=-3.5, b=-.033, S E=.016, t=-2.0$, and $b=-.040, S E=.018, t=-2.2)$. The interactions associated with identical and orthographic POF effects were not significant in GD $(b=.005, S E=.034, t=0.14 ; b=.034, S E=.033, t=1.05)$.

Most importantly, the interaction between group and homophonic POF effect was significant in GD $(b=.076, S E=.037, t=2.1)$, indicating that the homophonic POF effect was significant only among children $(b=-.078, S E=.026, t=-3.0)$ but not among adults $(b=-.002, S E=.018, t=-0.1)$. In an extended LMM, we tested the effect of familiarity on the reliance of phonological and orthographic information by including it as a covariate. The results demonstrated no main effect of, nor interactions with, character familiarity on fixation duration [all abs $(t$-values $)<1.8$ ]

Drieghe, Rayner, and Pollatsek (2008) proposed that POF effects are due to mislocated fixations caused by saccadic undershoots with intended landing position on the upcoming word. Specifically, due to its high information density in Chinese, if a fixation on the pretarget word is very close to the word ending, it may imply that the target word has been foveally processed, leading to a 'foveal-on-foveal' effect instead of a POF effect.

In another extended LMM, we included the first-fixation landing position on the pretarget word as a covariate to test if the observed phonological preprocessing for children was due to mislocated fixations or foveal processing of the upcoming words. The threeway interaction between homophonic POF effect, group and landing position was far from significance $(b=-.006, S E=.067, t=-0.9)$. Therefore, similar to findings reported by Zhou, Kliegl, and Yan (2013), there is no evidence supporting a view that the observed POF effect for children was caused by mislocated fixations. 


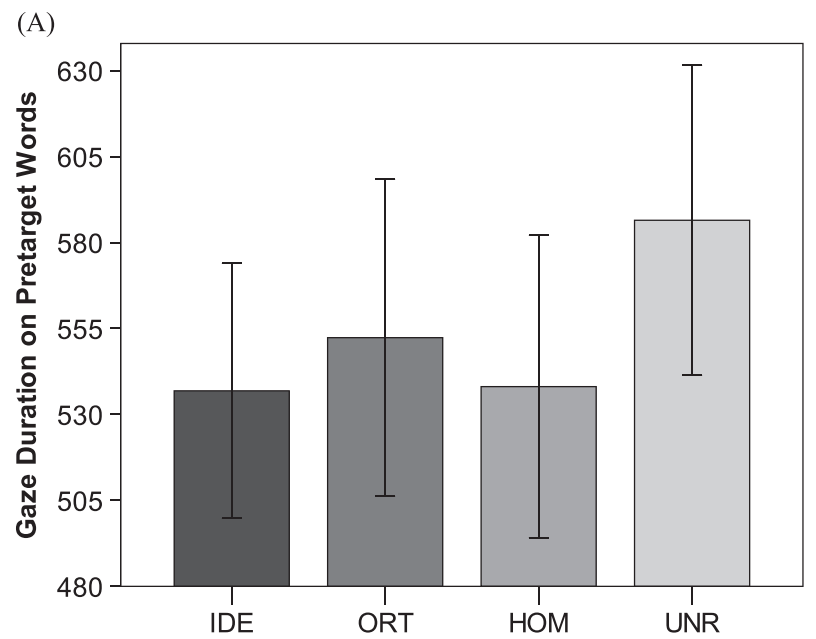

(B)

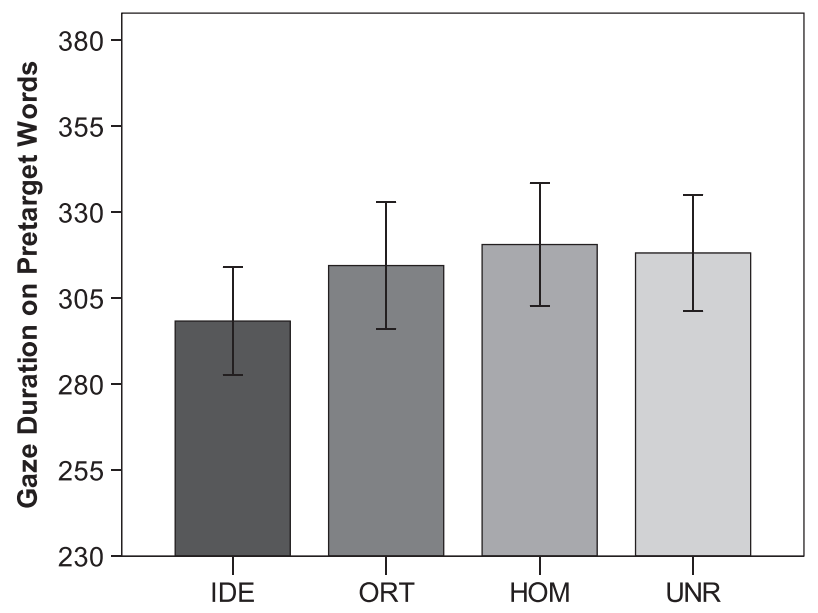

Figure 2. GDs on pretarget words (ms) in identical (IDE), orthographic (ORT), homophonic (HOM) and unrelated (UNR) conditions for children (A, top panel) and adults (B, bottom panel). Error bars show 95\% confidence intervals.

As a second test of the concerns above, following Inhoff, Radach, Starr, and Greenberg (2000), we carried out an analysis on likely 'nonerror' trials in which the target words were in the biologically defined foveal vision region. Although we suffered from a great loss of statistical power due to a decrease of observations (i.e., from 5,336 to 2,691), the critical finding still remained: the homophonic POF effect was significant only among children $(b=-.084, S E=.039, t=-2.2)$ but not among adults $(b=-.012, S E=.019, t=-0.7)$.

\section{Target word region}

Again, skilled readers read faster than beginning readers (GD: $b=-.427, S E=.055$, $t=-7.8$ ). The main effects of identical (FFD: $b=-.182, S E=.016, t=-11.0$ and GD: $b=-.362, S E=.024, t=-15.4$ ) and orthographic (FFD: $b=-.067, S E=.017$, $t=-4.0$ and GD: $b=-.114, S E=.024, t=-5.6)$ substitutions were highly reliable, 


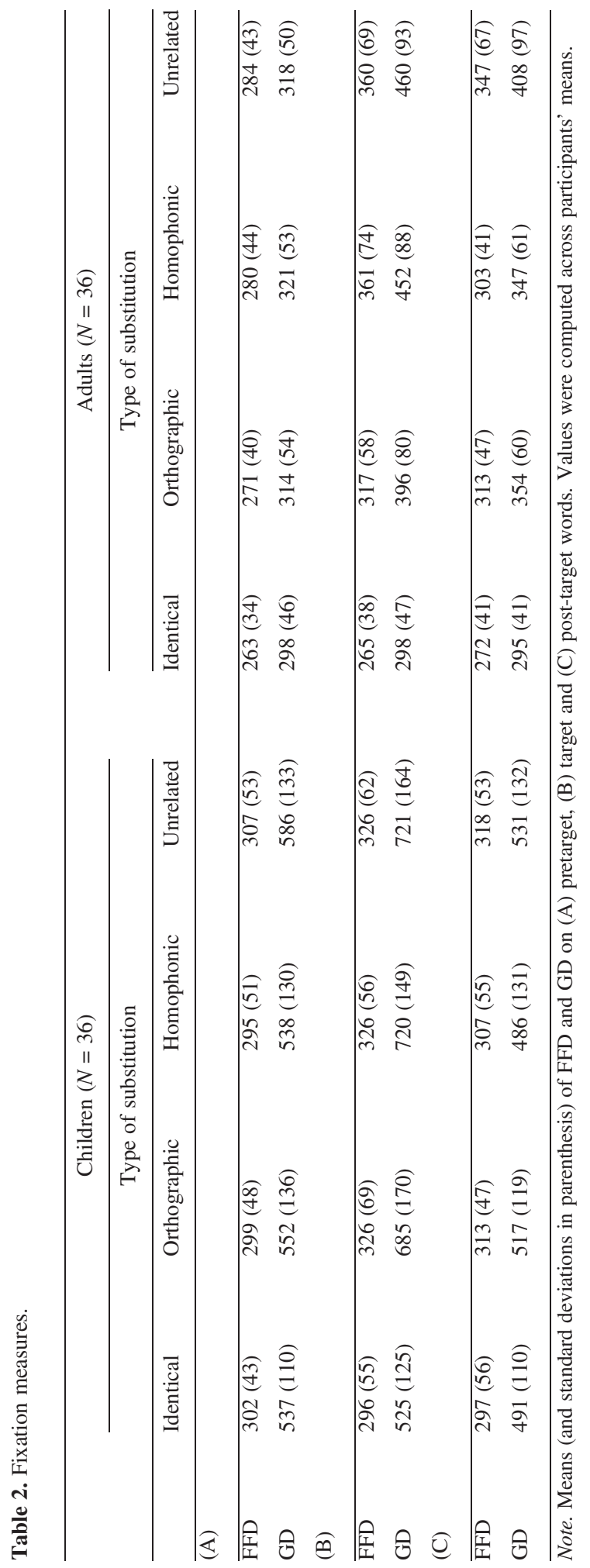


suggesting that both groups are able to make good use of orthographic information for foveal recovery. Critically, the interaction between foveal orthographic recovery effect and subject group was reliable in both FFD $(b=-.114, S E=.034, t=-3.4)$ and GD analyses $(b=-.083, S E=.041, t=-2.0)$, indicating that adults had robust recovery effects from orthographically similar substitutions (FFD: $b=-.122, S E=.018, t=-6.6$ and GD: $b=-.154, S E=.022, t=-6.9)$ whereas children only have a later and weaker recovery effect which appeared only in GD $(b=-.073, S E=.030, t=-2.5)$ but not in FFD $(b=-.009, S E=.023, t=-0.4)$. In contrast, there was little evidence for homophonic recovery [all abs $(t$-values $)<0.4$, for main effects and interactions associated with the homophonic condition] (Figure 3).

(A)

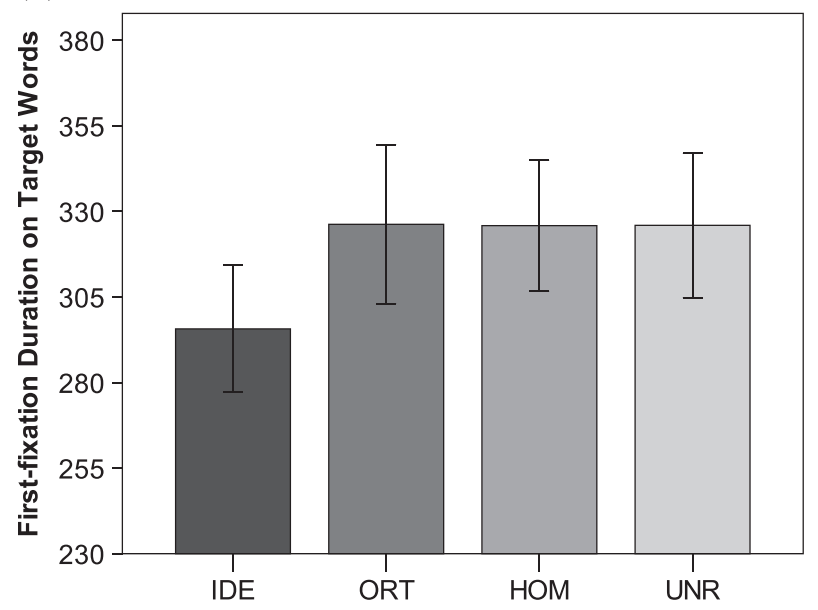

(B)

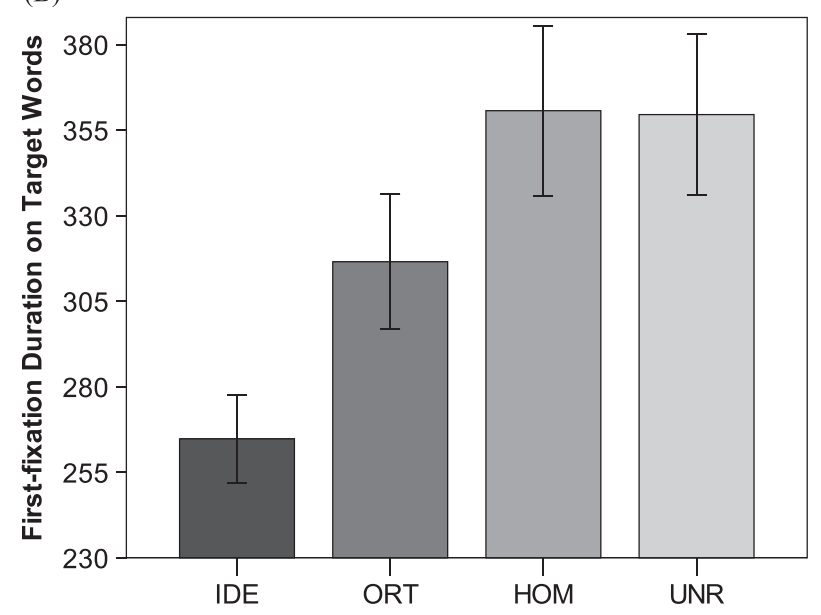

Figure 3. FFDs on target words (ms) in identical (IDE), orthographic (ORT), homophonic (HOM) and unrelated (UNR) conditions for children (A, top panel) and adults (B, bottom panel). Error bars show 95\% confidence intervals. 


\section{Post-target word region}

Similar to the pretarget and target regions, skilled readers read faster than beginning readers (GD: $b=-.235, S E=.053, t=-4.5$ ). Main effects were reliable for all three types of substitutions (for identical condition, FFD: $b=-.132, S E=.016, t=-8.3$ and GD : $b=-.159, S E=.022, t=-7.2$; for orthographic condition, FFD: $b=-.050, S E=.014$, $t=-3.5$ and GD $: b=-.064, S E=.019, t=-3.4$ and for homophonic condition, FFD: $b=-.074, S E=.015, t=-4.9$ and GD $: b=-.111, S E=.021, t=-5.3)$. The interactions between identical condition and subject group were reliable in both measures (FFD: $b=-.148, S E=.032, t=-4.7$ and GD: $b=-.204, S E=.044, t=-4.6)$. In addition, adults had better orthographic-based (for the interaction: FFD: $b=-.081, S E=.029$, $t=-2.8$ and GD: $b=-.105, S E=.038, t=-2.8)$ and phonological-based recovery abilities (for the interaction: FFD: $b=-.078, S E=.030, t=-2.6$ ) than children. Further decomposition of these interactions indicated that adults could effectively recover from both orthographic (FFD: $b=-.091, S E=.019, t=-4.8$ and GD: $b=-.117, S E=.023$, $t=-5.1$ ) and homophonic substitutions (FFD: $b=-.114, S E=.019, t=-5.9$ and GD: $b=-.131, S E=.023, t=-5.7)$, whereas children appeared to have only homophonic (FFD: $b=-.036, S E=.020, t=-1.8$ and GD: $b=-.093, S E=.028, t=-3.3$ ) but little orthographic [both abs $(t$-values $)<0.5$ ] recovery effect in the post-target region.

\section{Discussion}

The present study explored the reliance on phonology and orthography during the silent reading of Chinese sentences among beginning and skilled readers. As compared to many previous studies, the use of eye-tracking method during sentence reading allows us to observe lexical processing in a more natural reading task. Specifically, results on pre-target, target and post-target words correspond to parafoveal, fovea and post-lexical processing, respectively, providing a full picture of lexical processing from early to late stages. The novel contribution of the present study is that, when homophones were presented parafoveally, children processed the pretarget word more briefly as compared to unrelated substitutions, suggesting effective use of parafoveal phonology. In the target region, replicating Feng et al. (2001), we observed reliable early and late recovery effects due to orthographic similarity for adults, whereas the orthographic effect was limited to GD for children; there was little evidence for homophonic effect in both groups. In the post-target region, adults had better orthographic-based and phonological-based recovery abilities than children. Taken together, our results indicate that (1) Chinese beginning readers have early parafoveal activation of phonology during the silent reading of Chinese sentences, (2) this early activation diminishes with the development of reading skill and (3) adult Chinese readers rely more on direct access from orthography to semantics over all.

Although we manipulated character-level substitution, the present results shed light on both Chinese character and word processing. In lexical processing, character level activations of orthography, phonology and semantics jointly contribute to the recognition of compound word (Zhou, Marslen-Wilson, Taft, and Shu, 1999). For Chinese beginning readers, lexical compounding is considered a fundamental skill for reading and spelling (McBride-Chang et al., 2005). Due to the language-specific properties of Chinese script, it has been debated whether phonological mediation plays a role in lexical access: There is evidence on both sides when characters or words were presented foveally in isolation 
(e.g., Chen and Shu, 2001; Zhang, Perfetti, and Yang, 1999; Zhou and Marslen-Wilson, 1999). Feng et al. (2001) found no evidence for early phonological activation during the silent reading of Chinese sentences for adults. The findings of the present study are in principle in agreement with the findings reported by Feng et al. (2001) and Wong and Chen (1999): there is evidence for early recovery from orthographic similarity but not from homophone. Both types of information are used in a late stage. Late homophonic and orthographic recovery effects observed in the post-target region for adults imply that they rely on a combination of orthographic and phonological information for post-lexical processing.

The key question we ask in the present study is: do Chinese adults and children have different reliance on phonological recoding especially during parafoveal processing? Although Feng et al. (2001) showed that there was no early phonological activation among Chinese adult readers, it should not be taken for granted that early phonological activation is absent also among beginning readers. Arguably, this is because the relative predominance of phonology in reading can be modulated by reading skills. For instance, Jared, Levy, and Rayner (1999) found that poor readers have larger benefit recovering from homophonic words than good readers, suggesting that good readers use a direct route to access semantics whereas poor readers need phonological mediation. We did observe a stronger homophonic POF effect in the pretarget region among children, suggesting phonological recovery from the parafovea. It is reasonable to interpret this result as evidence supporting a notion that Chinese children have earlier activation of phonology than adults. Previous studies on orthographic and phonological development mainly focused only on foveal processing during isolated word recognition or sentence reading, and little is known about lexical processing priority in the parafoveal. Therefore, the novel contribution of the present study is the early phonological activation as indicated by the POF effect for children.

The finding that phonological recoding is of greater importance among children could be attributed to the fact that beginning readers are more used to reading aloud in which phonology is fully decoded (Manguel, 1996). It has been documented that orthographic depth of the writing system has an influence on phonological processing: English-speaking children rely less on phonology as compared to Spanish-, German- or French-speaking children (Sprenger-Charolles, Nunes, \& Bryant, 2003b), which may suggest a trivial role of phonology among Chinese children because the orthography-to-phonology mapping is opaque in Chinese. In fact, when children are learning to read in Mainland China, on school entry, they learn hanyu pinyin, which is a shallow, alphabetic-based orthography that provides a way to represent the sound of Chinese characters. Yan, Miller, Li, and Shu (2008) reported that beginning readers of Chinese rely on hanyu pinyin when they encounter unlearned words which represent familiar concepts to understand the sentences, suggesting that lexical access can be made using phonological mediation. In addition, Cheung and Chen (2004) compared students who grew up in Guangzhou and had learned hanyu pinyin and students who grew up in Hong Kong and learned Chinese without any sound-based aiding system. They found that participants who had been taught hanyu pinyin outperformed their counterparts who had not learned it in phonological awareness tasks. Therefore, taken hanyu pinyin into consideration, it is not surprising that Chinese beginning readers reply on phonological recoding.

It is also not surprising that unskilled readers would take advantage of whatever cues might be available to them to guide lexical access. Gough (1993) showed that very early readers will use even clearly extraneous cues (in this case a thumbprint) to identify words; it is not surprising that young readers will take advantage of phonological cues that are partially and occasionally useful even though they are not very reliable. 
For skilled readers, there is vast evidence suggesting that alphabetic readers have early access to parafoveal phonology. For example, Pollatsek, Lesch, Morris, and Rayner (1992) demonstrated that, parafoveally presented homophonic previews facilitated processing of the target word in FFD, relative to non-homophonic preview words. In contrast, although remnants of inner voice can still be found in silent reading among Chinese adults (e.g., Yan, Luo, and Inhoff, 2014), it is commonly accepted that pure parafoveal phonological effects without orthographic similarity during the silent reading of Chinese sentences may not be as effective (see also Tsang and Chen, 2012, for a review): First, homophonic preview effects have been consistently shown only for GD during the silent reading of Chinese sentences (Liu, Inhoff, Ye, and Wu, 2002; Tsai, Lee, Tzeng, Hung, and Yen, 2004; Yan et al., 2009). Arguably, as GD includes refixations, it is usually interpreted as an index for a relatively later duration measure than FFD (Inhoff, 1984). Second, effective parafoveal phonological extraction is highly restricted to favourable situations including long preview duration (i.e., fixation duration on pretarget words) and high parafoveal processing efficiency afforded by high-frequency pretarget words (Tsai, Kliegl, and Yan, 2012). Third, recent evidence suggests that a homophonic POF effect is limited to oral reading but not in silent reading, because the explicit demand of phonological processing in oral reading increases the parafoveal processing of phonology (Pan et al., 2016). In agreement with these results, no evidence for preprocessing of phonology among adult Chinese readers was observed in the present study. Contrary to the limited phonological effect, there were reliable orthographic recovery effects for adults in the current study and Feng et al. (2001). According to the model of Zhou and Marslen-Wilson (1999), Chinese character recognition is predominantly orthography based whereas phonology may be a by-product of lexical access. Again, these results jointly indicate the logographic feature of the Chinese writing system.

Character consistency (whether all the characters with the same phonetic radical have the same pronunciation; Fang, Horng, and Tzeng, 1986) and regularity effects (whether the sound of a character is identical with that of its phonetic radical; Lien, 1985) of Chinese phonograms have been well documented to influence character recognition for children. For instance, Shu, Anderson, and Wu (2000) found that Children from grade 2 to grade 6 all produced significant regularity effect. Yang and Peng (1997) observed that regularity effect was reliable only for Children in grade 3 but not in grade 6 . These findings also suggest that children could rely on phonological information for reading. As for the current study, we mainly selected non-phonograms for the manipulation of character substitution. How Chinese readers use phonetic sub-lexical information for recovery is beyond the scope of the present study. It will be of great theoretical importance for future research to explore this issue.

There was an absence of foveal phonological effect, which emerged again in the post-target region for children. There has been evidence that certain effects show up early and disappear later in fixation measures (e.g., Calvo and Meseguer, 2002; Pollatsek et al., 1992). We suspect that phonological processing in target words was interrupted for some reasons, which may be further explored with more sensitive techniques such as the gaze-contingent boundary paradigm (Rayner, 1975) and the gaze-contingent auditory distractor paradigm (Inhoff, Connine, Eiter, Radach, and Heller, 2004).

To summarise, in the present study, we extend our current understanding about the reliance on orthography and phonology from foveal to parafoveal processing; that is, how various types of information are processed prior to a word is fixated. The recovery effect from parafoveal homophones was observed during the silent reading of Chinese 
sentences for beginning readers but not for adults, suggesting that Chinese beginning readers may rely on phonological mediation. The fact that young readers take advantage of phonological aspects in Chinese reading suggests that it may be useful to teach phonological cues about characters to beginning readers, even if those cues are largely discarded once one becomes a skilled reader.

\section{Acknowledgements}

This research was supported by Natural Science Foundation of China (31500886, 31271082, 31671126, 31611130107), Beijing Advanced Innovation Center for Imaging Technology (BAICIT-2016018), Deutsche Forschungsgemeinschaft Grant KL 955/18, Research Fund for the Talented Person of Beijing City Grant (2014000020124G238) and Beijing Municipal Science and Technology Commission (Z151100003915122).

\section{References}

Bates, D., Maechler, M., Bolker, B., \& Walker, S. (2016). lme4: Linear mixed-effects models using Eigen and S4. R package version 1.1-12. Retrieved from https://cran.r-project.org/web/packages/lme4/index.html

Beijing Language Institute Publisher (1986). Modern Chinese word frequency dictionary. Beijing, China: Beijing Language Institute Publisher (in Chinese).

Calvo, M.G. \& Meseguer, E. (2002). Eye movements and processing stages in reading: Relative contribution of visual, lexical, and contextual factors. The Spanish Journal of Psychology, 5(1), 66-77. DOI:10.1017/ S1138741600005849.

Chen, H.-C. \& Shu, H. (2001). Lexical activation during the recognition of Chinese characters: Evidence against early phonological activation. Psychonomic Bulletin and Review, 8(3), 511-518. DOI:10.3758/BF03196186.

Cheng, C.M. (1981). Perception of Chinese characters. Acta Psychologica Taiwanica, 23, 137-153.

Cheung, M.-H. \& Chen, H.-C. (2004). Early orthographic experience modifies both phonological awareness and on-line speech processing. Language and Cognitive Porcesses, 19, 1-28. DOI:10.1080/01690960344000071.

Coltheart, V., Avons, S.E. \& Trollope, J. (1990). Articulatory suppression and phonological codes in reading for meaning. The Quarterly Journal of Experimental Psychology, 42(2), 375-399. DOI:10.1080/ 14640749008401227.

Coltheart, M., Rastle, K., Perry, C., Langdon, R. \& Ziegler, J. (2001). DRC: A dual route cascaded model of visual word recognition and reading aloud. Psychological Review, 108(1), 204-256. DOI:10.1037/0033295X.108.1.204.

R Core Team. (2016). R: A language and environment for statistical computing. $R$ Foundation for Statistical Computing, Vienna, Austria. Retrieved from http://www.R-project.org/

Daneman, M. \& Reingold, E.M. (1993). What eye fixations tell us about phonological recoding during reading. Canadian Journal of Experimental Psychology, 47(2), 153-178. DOI:10.1037/h0078818.

Doctor, E.A. \& Coltheart, M. (1980). Children's use of phonological encoding when reading for meaning. Memory and Cognition, 8(3), 195-209. DOI:10.3758/BF03197607.

Drieghe, D., Rayner, K. \& Pollatsek, A. (2008). Mislocated fixations can account for parafoveal-on-foveal effects in eye movements during reading. Quarterly Journal of Experimental Psychology, 61(8), 1239-1249. DOI:10.1080/17470210701467953.

Ehri, L.C. (1992). Reconceptualizing the development of sight word reading and its relationship to recoding. In P. B. Gough, L.C. Ehri \& R. Treiman (Eds.), Reading acquisition, (pp. 107-143). Hillsdale, NJ: Erlbaum.

Engbert, R. \& Kliegl, R. (2003). Microsaccades uncover the orientation of covert attention. Vision Research, 43 (9), 1035-1045. DOI:10.1016/S0042-6989(03)00084-1.

Fang, S.P., Horng, R. \& Tzeng, O. (1986). Consistency effects in the Chinese character and pseudo-character naming tasks. In H.R. Kao \& R. Hoosain (Eds.), Linguistics, psychology and the Chinese language, (pp. 11-21). Hong Kong: University of Hong Kong, Centre for Asian Studies. 
Feng, G., Miller, K., Shu, H. \& Zhang, H. (2001). Rowed to recovery: The use of phonological and orthographic information in reading Chinese and English. Journal of Experimental Psychology: Learning, Memory, and Cognition, 27(4), 1079-1100. DOI:10.1037/0278-7393.27.4.1079.

Frith, U. (1985). Beneath the surface of developmental dyslexia. In K. Patterson, J. Marshall \& M. Coltheart (Eds.), Surface dyslexia, (pp. 301-330). Hillsdale, NJ: Lawrence Erlbaum Associates.

Gilliard, F.D. (1993). More silent reading in antiquity: Non omne verbum sonabat. Journal of Biblical Literature, 112(4), 689-694.

Gough, P.B. (1993). The beginning of decoding. Reading and Writing, 5(2), 181-192.

Ho, C.S.H. \& Bryant, P. (1997). Phonological skills are important in learning to read Chinese. Developmental Psychology, 33(6), 946. DOI:10.1037/0012-1649.33.6.946.

Hoosain, R. (1991). Psycholinguistic implications for linguistic relativity: A case study of Chinese. Hillsdale, NJ: Erlbaum.

Hu, C.F. \& Catts, H.W. (1998). The role of phonological processing in early reading ability: What we can learn from Chinese. Scientific Studies of Reading, 2(1), 55-79. DOI:10.1207/s1532799xssr0201_3.

Huang, H.S. \& Hanley, J.R. (1995). Phonological awareness and visual skills in learning to read Chinese and English. Cognition, 54(1), 73-98. DOI:10.1016/0010-0277(94)00641-W.

Inhoff, A.W. (1984). Two stages of word processing during eye fixations in the reading of prose. Journal of Verbal Learning and Verbal Behavior, 23(5), 612-624. DOI:10.1016/S0022-5371(84)90382-7.

Inhoff, A.W., Connine, C., Eiter, B., Radach, R. \& Heller, D. (2004). Phonological representation of words in working memory during sentence reading. Psychonomic Bulletin and Review, 11, 320-325. DOI:10.3758/BF03196577.

Inhoff, A.W. \& Liu, W. (1998). The perceptual span and oculomotor activity during the reading of Chinese sentences. Journal of Experimental Psychology: Human Perception and Performance, 24, $20-34$. DOI:10.1037/0096-1523.24.1.20.

Inhoff, A.W., Radach, R., Starr, M. \& Greenberg, S. (2000). Allocation of visuo-spatial attention and saccade programming in reading. In A. Kennedy, R. Radach, D. Heller \& J. Pynte (Eds.), Reading as a visual process, (pp. 221-246). Oxford, England: Elsevier.

Inhoff, A.W. \& Topolski, R. (1994). Use of phonological codes during eye fixations in reading and in on-line and delayed naming tasks. Journal of Memory and Language, 33(5), 689-713. DOI:10.1006/jmla.1994.1033.

Jared, D., Ashby, J., Agauas, S.J. \& Levy, B.A. (2016). Phonological activation of word meanings in grade 5 readers. Journal of Experimental Psychology: Learning, Memory, and Cognition, 42(4), 524-541. DOI:10.1037/xlm0000184.

Jared, D., Levy, B.A. \& Rayner, K. (1999). The role of phonology in the activation of word meanings during reading: Evidence from proofreading and eye movements. Journal of Experimental Psychology: General, 128(3), 219-264. DOI:10.1037/0096-3445.128.3.219.

Kliegl, R., Masson, M.E.J. \& Richter, E.M. (2010). A linear mixed model analysis of masked repetition priming. Visual Cognition, 18, 655-681. DOI:10.1080/13506280902986058.

Kliegl, R., Risse, S. \& Laubrock, J. (2007). Preview benefit and parafoveal-on-foveal effects from word $n+2$. Journal of Experimental Psychology: Human Perception and Performance, 33(5), 1250-1255. DOI:10.1037/ 0096-1523.33.5.1250.

Laubrock, J. \& Kliegl, R. (2015). The eye-voice span during reading aloud. Frontiers in Psychology, 6, 1432. DOI:10.3389/fpsyg.2015.01432.

Lee, C.Y., Tsai, J.L., Su, E.C.I., Tzeng, O.J.L. \& Hung, D.L. (2005). Consistency, regularity, and frequency effects in naming Chinese characters. Language and Linguistics, 6, 75-107.

Lien, Y.W. (1985). Consistency of phonetic clues in the Chinese phonograms and their naming latencies. Taipei: National Taiwan University MA thesis.

Liu, W., Inhoff, A.W., Ye, Y. \& Wu, C. (2002). Use of parafoveally visible characters during the reading of Chinese sentences. Journal of Experimental Psychology: Human Perception and Performance, 28(5), 1213-1227. DOI:10.1037/0096-1523.28.5.1213.

Manguel, A. (1996). A history of reading. New York: Viking.

McBride-Chang, C., Cho, J.-R., Liu, H., Wagner, R.K., Shu, H., Zhou, A. et al. (2005). Changing models across cultures: Associations of phonological awareness and morphological structure awareness with vocabulary and word recognition in second graders from Beijing, Hong Kong, Korea, and the United States. Journal of Experimental Child Psychology, 92, 140-160. DOI:10.1016/j.jecp.2005.03.009.

McConkie, G.W. \& Rayner, K. (1975). The span of the effective stimulus during a fixation in reading. Perception and Psychophysics, 17, 578-586. DOI:10.3758/BF03203972.

Pan, J., Yan, M. \& Laubrock, J. (2017). Perceptual span in oral reading: The case of Chinese. Scientific Studies of Reading.. DOI:10.1080/10888438.2017.1283694. 
Pan, J., Laubrock, J. \& Yan, M. (2016). Parafoveal processing in silent and oral reading: Reading mode influences the relative weighting of phonological and semantic information in Chinese. Journal of Experimental Psychology: Learning, Memory, and Cognition, 42(8), 1257-1273. DOI:10.1037/xlm0000242.

Plaut, D.C., McClelland, J.L., Seidenberg, M.S. \& Patterson, K. (1996). Understanding normal and impaired word reading: Computational principles in quasi-regular domains. Psychological Review, 103(1), 56-115. DOI:10.1037/0033-295X.103.1.56.

Pollatsek, A., Lesch, M., Morris, R.K. \& Rayner, K. (1992). Phonological codes are used in integrating information across saccades in word identification and reading. Journal of Experimental Psychology: Human Perception and Performance, 18(1), 148-162. DOI:10.1037/0096-1523.18.1.148.

Rayner, K. (1975). The perceptual span and peripheral cues in reading. Cognitive Psychology, 7(1), 65-81. DOI:10.1016/0010-0285(75)90005-5.

Rayner, K., Pollatsek, A. \& Binder, K.S. (1998). Phonological codes and eye movements in reading. Journal of Experimental Psychology: Learning, Memory, and Cognition, 24(2), 476-479. DOI:10.1037/02787393.24.2.476.

Saenger, P. (1997). Space between words: The origins of silent reading. Stanford, CA: Stanford University Press.

Seidenberg, M.S. \& McClelland, J.L. (1989). A distributed, developmental model of word recognition and naming. Psychological Review, 96(4), 523-568. DOI:10.1037/0033-295X.96.4.523.

Seymour, P.H. (1997). Foundations of orthographic development. In C. Perfetti, L. Rieben \& M. Fayol (Eds.), Learning to spell: Research, theory, and practice across languages, (pp. 319-337). Mahwah, NJ: Lawrence Erlbaum Associates.

Shu, H., Anderson, R.C. \& Wu, N. (2000). Phonetic awareness: Knowledge of orthography-phonology relationships in the character acquisition of Chinese children. Journal of Educational Psychology, 92(1), 56-62. DOI:10.1037/0022-0663.92.1.56.

Shu, H., Chen, X., Anderson, R.C., Wu, N. \& Xuan, Y. (2003). Properties of school Chinese: Implications for learning to read. Child Development, 74(1), 27-47. DOI:10.1111/1467-8624.00519.

Shu, H., Peng, H. \& McBride-Chang, C. (2008). Phonological awareness in young Chinese children. Developmental Science, 11(1), 171-181. DOI:10.1111/j.1467-7687.2007.00654.x.

Siok, W.T. \& Fletcher, P. (2001). The role of phonological awareness and visual-orthographic skills in Chinese reading acquisition. Developmental Psychology, 37(6), 886-899. DOI:10.1037/0012-1649.37.6.886.

Sparrow, L. \& Miellet, S. (2002). Activation of phonological codes during reading: Evidence from errors detection and eye movements. Brain and Language, 81(1), 509-516. DOI:10.1006/brln.2001.2543.

Sprenger-Charolles, L., Nunes, T. \& Bryant, P. (2003b). Reading acquisition: Cross linguistic data. In T. Nunes \& P. Bryant (Eds.), Handbook of children's literacy, (pp. 43-66). Dordrecht: Kluwer.

Sprenger-Charolles, L., Siegel, L.S., Béchennec, D. \& Serniclaes, W. (2003a). Development of phonological and orthographic processing in reading aloud, in silent reading, and in spelling: A four-year longitudinal study. Journal of Experimental Child Psychology, 84(3), 194-217. DOI:10.1016/S0022-0965(03) 00024-9.

Taft, M. \& Zhu, X. (1995). The representation of bound morphemes in the lexicon: A Chinese study. In L.B. Feldman (Ed.), Morphological aspects of language processing, (pp. 293-316). Hillsdale, NJ: Lawrence Erlbaum Associates Inc.

Tao, B.Y. (2012). Hierarchical Chinese character list for primary school teaching. [Original work in Chinese]. Shanghai: Dictionary Press.

Treiman, R., Freyd, J.J. \& Baron, J. (1983). Phonological recording and use of spelling-sound rules in reading of sentences. Journal of Verbal Learning and Verbal Behavior, 22(6), 682-700. DOI:10.1016/S0022-5371(83) 90405-X.

Tsai, J.L., Kliegl, R. \& Yan, M. (2012). Parafoveal semantic information extraction in traditional Chinese reading. Acta Psychologica, 141(1), 17-23. DOI:10.1016/j.actpsy.2012.06.004.

Tsai, J. L. \& Lee, C. Y. (2008). The influence of character combinability on the optimal viewing position of Chinese words. The Fifteenth Annual Meeting of Society for the Scientific Study of Reading, Asheville, North Carolina, USA.

Tsai, J.L., Lee, C.Y., Tzeng, O.J., Hung, D.L. \& Yen, N.S. (2004). Use of phonological codes for Chinese characters: Evidence from processing of parafoveal preview when reading sentences. Brain and Language, 91(2), 235-244. DOI:10.1016/j.bandl.2004.02.005.

Tsang, Y.K. \& Chen, H.C. (2012). Eye movement control in reading: Logographic Chinese versus alphabetic scripts. The PsyCh Journal, 1, 128-142. DOI:10.1002/pchj.10.

Van Orden, G.C. (1987). A ROWS is a ROSE: Spelling, sound, and reading. Memory and Cognition, 15(3), 181-198. DOI:10.3758/BF03197716. 
Wheeler, D.D. (1970). Processes in word recognition. Cognitive Psychology, 1, 59-85. DOI:10.1016/0010-0285 (70)90005-8.

Wong, K.F.E. \& Chen, H.C. (1999). Orthographic and phonological processing in reading Chinese text: Evidence from eye fixations. Language and Cognitive Processes, 14(5-6), 461-480. DOI:10.1080/016909699386158.

Yan, M., Luo, Y. \& Inhoff, A.W. (2014). Syllable articulation influences foveal and parafoveal processing of words during the silent reading of Chinese sentences. Journal of Memory and Language, 75, 93-103. DOI:10.1016/j.jml.2014.05.007.

Yan, M., Miller, K.F., Li, H. \& Shu, H. (2008). What is the place for pinyin in beginning Chinese reading? Evidence from eye-movement research. In K. Rayner, D. Shen, X. Bai \& G. Yan (Eds.), Cognitive and cultural influences on eye movements, (pp. 343-360). New York: Psychology Press.

Yan, M., Richter, E.M., Shu, H. \& Kliegl, R. (2009). Readers of Chinese extract semantic information from parafoveal words. Psychonomic Bulletin and Review, 16(3), 561-566. DOI:10.3758/PBR.16.3.561.

Yan, M. \& Sommer, W. (2015). Parafoveal-on-foveal effects of emotional word semantics in reading Chinese sentences: Evidence from eye movements. Journal of Experimental Psychology: Learning, Memory, and Cognition, 41(4), 1237-1243. DOI:10.1037/xlm0000095.

Yan, M., Zhou, W., Shu, H. \& Kliegl, R. (2015). Perceptual span depends on font size during reading of Chinese sentences. Journal of Experimental Psychology: Human Perception and Performance, 41(1), 209-219. DOI:10.1037/a0038097.

Yang, H. \& Peng, D.L. (1997). The learning and naming of Chinese characters of elementary school children. In H.C. Chen (Ed.), Cognitive processing of Chinese and related Asian languages, (pp. 323-346). Hong Kong: Chinese University Press.

Yang, J., Wang, S., Xu, Y. \& Rayner, K. (2009). Do Chinese readers obtain preview benefit from word $\mathrm{n}+2$ ? Evidence from eye movements. Journal of Experimental Psychology: Human Perception and Performance, 35(4), 1192-1204. DOI:10.1037/a0013554.

Zhang, S., Perfetti, C.A. \& Yang, H. (1999). Whole word, frequency-general phonology in semantic processing of Chinese characters. Journal of Experimental Psychology: Learning, Memory, and Cognition, 25(4), 858-875. DOI:10.1037/0278-7393.25.4.858.

Zhou, W., Kliegl, R. \& Yan, M. (2013). A validation of parafoveal semantic information extraction in reading Chinese. Journal of Research in Reading, 36(S1), S51-S63. DOI:10.1111/j.1467-9817.2013.01556.x.

Zhou, X. \& Marslen-Wilson, W. (1999). Phonology, orthography, and semantic activation in reading Chinese. Journal of Memory and Language, 41(4), 579-606. DOI:10.1006/jmla.1999.2663.

Zhou, X., Marslen-Wilson, W., Taft, M. \& Shu, H. (1999). Morphology, orthography, and phonology in reading Chinese compound words. Language and Cognitive Processes, 14, 525-565.

Zhou, Y. (1978). To what extent are the "phonetics" of present-day Chinese characters still phonetic. [Original work in Chinese]. Zhongguo Yuwen, 146, 172-177.

Ziegler, J.C., Bertrand, D., Lété, B. \& Grainger, J. (2014). Orthographic and phonological contributions to reading development: Tracking developmental trajectories using masked priming. Developmental Psychology, 50(4), 1026-1036. DOI:10.1037/a0035187.

\section{Appendix}

\begin{tabular}{llllll}
\hline & & \multicolumn{5}{c}{ Type of Substitution } \\
\hline ID & Sentence & IDT & ORT & HOM & UNR \\
1 & 中央领导表扬县官出色的工作业绩。 & 县 & 具 & 限 & 或 \\
2 & 检查和清理这些货物需要很长的时间。 & 货 & 贷 & 获 & 英 \\
3 & 人们发现人体血液里面含有对抗病菌的物质。 & 血 & 皿 & 穴 & 卢 \\
4 & 明天的春游活动由于天气原因被取消了。 & 由 & 田 & 尤 & 父 \\
5 & 昨天剩下的馒头就像石头一样又硬又难吃。 & 石 & 右 & 十 & 干 \\
6 & 军队的长官命令士兵帮助人民群众。 & 士 & 土 & 示 & 反 \\
7 & 同学之间的深厚友谊值得永远珍惜。 & 友 & 发 & 有 & 产 \\
8 & 班主任老师正高声斥责上课迟到的同学。 & 斥 & 斤 & 赤 & 色 \\
9 & 我们每个人大脑思维方式有着千差万别。 & 思 & 恩 & 司 & 受
\end{tabular}


10

勇敢的士兵握住盾牌冲出敌军的包围。

人们在公共场所坚立标语来禁止吸烟。

民警使出全身力气抓紧想要逃跑的小偷。

\section{博物馆的文物都是研究古代文化的重要资料。} 老师建议同学们及时复习当天学习的课程。 因为下雨而取消户外活动的消息令人失望。 战士们在野外只好依靠吃草根充饥。 这个地区含有异常丰富的石油和天然气。 这段连续的文字缺少句号作为间隔的标志。 在场所有人围绕冠军欢呼和庆祝胜利。 父母希望他通过上学读书改变自己的命运。 我们烹饪和食用菌类应该注意饮食安全。 这个小岛上的人们使用贝壳代替钱的功能。 爸爸昨天买的红色金鱼受到儿子喜爱。 世界上不同国家庆祝元旦迎接新年的方式都不同。 他已经养成了坚持早晨锻炼的好习惯。 图书馆向参观者提供午饭以及各种饮料。 我们国家的人口数量目前已经达到了十四亿。 海岛地区发生地震几率明显高于内陆。 同学们正在学习究竟如何制作风筝。 这本书是一部描述未来科技的著作。 一般人都习惯使用右手吃饭和写字。 他抬头突然看见云朵好像棉花糖一样。 
二十世纪的电脑革命促进世界快速发展。

革草格总 典礼当天参加升旗仪式的人都非常兴奋。 受到惊吓的同学们拼命向前奔跑和喊叫。 无数的小鱼在河流干枯过后渴死了。 这种金属可以增强导弹外壳的坚固程度。 这个教育机构能帮助儿童提高阅读的能力。 北半球的白天在每年夏至达到最长时间 古时候人们认为具有匀称体型的马跑得最快。 老师告诉大家制定目标应该切合实际。 北方地区的秋季旱灾严重影响了小麦收成。 老师用药水将昆虫尸体处理成标本。

非常高的楼房必须采用十分安全的玻璃。 他和哥哥都希望今年过年收到更多压岁钱。 湖泊是在多种自然因素综合作用下形成的。 受到表扬的孩子心里充满了无限希望。 小学校长在昨天闭幕典礼上发表了讲话。 这种草药能帮助止血促进伤口恢复。 这种冲动的行为未必就是勇敢的表现。 科学家发现优质茶叶含有很多有益物质。 他向父母提出无礼要求之后被拒绝了。 春天稻田里面禾苗高度超过了一个大人。 老师会给同学们安排自由活动的时间。 他的哥哥将在今年九月参加全国钢琴比赛。 今年过年我们全家乘坐飞机到海南去玩。 市长应该尽快想到办法制止随地吐痰。 监狱应该是协助囚犯认识和改正错误的地方。 他们发现这家公司工作人员都非常勤奋。 傍晚的天空因为夕阳照射而发出红色的光。 农夫建议树苗间隔不能太大也不能太小。 乞正为灾区捐钱的场面令人感动得流下泪来。 村民们在秋天尽情享受丰收的喜悦和欢乐。 在期末考试过后我们可以尽情玩要。 他从小喜欢收集各种颜色的花瓣和叶子。 遇到危险情况要根据具体情况想办法。 王芳和她的同学见面从来不打招呼。 这位著名画家带领徒弟前往北京参加比赛。 司机因为违背交通规则而受到了处罚。

Wei Zhou Faculty member of Department of Psychology in Capital Normal University. BA (2009, Psychology, School of Psychology, Beijing Normal University P.R. China), PhD (2014, Psychology, State Key Laboratory of Cognitive Neuroscience and Learning, Beijing Normal University P.R. China). Cognitive Psychology. Eye movement control in reading and its neural mechanism; Reading development and dyslexia 
Hua Shu Professor. BA (1983, Psychology, Department of Psychology, Beijing Normal University P.R. China), PhD (1992, Psychology, Department of Psychology, Beijing Normal University P.R. China). Cognitive Psychology and Developmental Psychology. Reading development and dyslexia.

Kevin Miller Professor. BA (1977, Psychology), PhD (1982, Child and School Psychology, Department of Child Psychology \& Psychology in the Schools, University of Minnesota, USA). Developmental Psychology and Educational Psychology. Nature and sources of early mathematical and literacy development, on cross-cultural similarities and differences in academic learning and performance, and more recently on utilizing video records to engage teachers with issues of instructional practice.

Ming Yan Research scientist. BA (2003, Psychology, Department of Psychology, Beijing Normal University P.R. China), PhD (2008, Psychology, State Key Laboratory of Cognitive Neuroscience and Learning, Beijing Normal University P.R. China). Cognitive Psychology. Eye movement control mechanism in reading Chinese script, including (1) basic reading unit for Chinese language, whether readers select word unit as target for saccade even though in lack of explicit word boundary, (2) parafoveal processing in reading, given the big differences between Chinese and alphabetic languages, what information is available before fixating a word, and (3) use mathematical models to simulate eye movement pattern in reading Chinese script.

Received 24 July 2015; revised version received 29 January 2017.

Address for correspondence: Ming Yan, Department of Psychology, University of Potsdam, Karl-Liebknecht-Str. 24/25, 14476 Potsdam-Golm, Germany. E-mail: mingyan@uni-potsdam.de 